\title{
Identification of Novel Alleles of the Rice Blast-Resistance Gene Pi9 through Sequence-Based Allele Mining
}

\author{
Ying Zhou ${ }^{1 *+} \mathbb{D}$, Fang $\mathrm{Lei}^{2+}$, Qiong Wang ${ }^{1}$, Weicong He${ }^{1}$, Bin Yuan ${ }^{3,4}$ and Wenya Yuan ${ }^{5^{*}}$
}

\begin{abstract}
Background: As rice (Oryza sativa) is the staple food of more than half the world's population, rice production contributes greatly to global food security. Rice blast caused by the fungus Magnaporthe oryzae (M. oryzae) is a devastating disease that affects rice yields and grain quality, resulting in substantial economic losses annually. Because the fungus evolves rapidly, the resistance conferred by most the single blast-resistance genes is broken after a few years of intensive agricultural use. Therefore, effective resistance breeding in rice requires continual enrichment of the reservoir of resistance genes, alleles, or QTLs. Seed banks represent a rich source of genetic diversity; however, they have not been extensively used to identify novel genes and alleles.
\end{abstract}

Results: We carried out a large-scale screen for novel blast-resistance alleles in 1883 rice varieties from major riceproducing areas across China. Of these, 361 varieties showed at least moderate resistance to natural infection by rice blast at rice blast nurseries in Enshi and Yichang, Hubei Province. We used sequence-based allele mining to amplify and sequence the allelic variants of the major rice blast-resistance genes at the Pi2/Pi9 locus of chromosome 6 from the 361 blast-resistant varieties, and the full-length coding region of this gene could be amplified from 107 varieties. Thirteen novel Pi9 alleles (named Pi9-Type1 to Pig-Type13) were identified in these 107 varieties based on comparison to the Pi9 referenced sequence. Based on the sequencing results, the Pi2/Pi9 locus of the 107 varieties was divided into 15 genotypes (including three different genotypes of Pig-Type5). Fifteen varieties, each representing one genotype, were evaluated for resistance to $34 \mathrm{M}$. oryzae isolates. The alleles from seven varieties with the highest resistance and widest resistance spectra were selected for transformation into the susceptible variety J23B to construct near-isogenic lines (NILs). These NILs showed resistance in a field test in Enshi and Yichang, indicating that the seven novel rice blast-resistance tandem-repeat regions at the Pi2/Pi9 locus of chromosome 6 could potentially serve as a genetic resource for molecular breeding of resistance to rice blast.

Conclusions: The thirteen novel Pi9 alleles identified in this study expand the list of available of blast-resistance alleles. Seven tandem-repeat regions of the Piz/Pi9 locus from different donors were characterized as broadspectrum rice blast-resistance fragments; these donors enrich the genetic resources available for rice blast-resistance breeding programs.

Keywords: Gene conversion, Nucleotide diversity, Pi9, R genes, Resistance gene alleles, Rice blast

\footnotetext{
*Correspondence: 18062565621@163.com; wyyuan@hubu.edu.cn

${ }^{\dagger}$ Ying Zhou and Fang Lei contributed equally to this work.

'College of Life Science and Health, Wuhan University of Science and

Technology, Wuhan 430065, People's Republic of China

${ }^{5}$ College of Life Sciences, Hubei University, Wuhan 430062, People's Republic of China

Full list of author information is available at the end of the article
}

\section{Springer Open}

(๑) The Author(s). 2020 Open Access This article is licensed under a Creative Commons Attribution 4.0 International License, which permits use, sharing, adaptation, distribution and reproduction in any medium or format, as long as you give appropriate credit to the original author(s) and the source, provide a link to the Creative Commons licence, and indicate if changes were made. The images or other third party material in this article are included in the article's Creative Commons licence, unless indicated otherwise in a credit line to the material. If material is not included in the article's Creative Commons licence and your intended use is not permitted by statutory regulation or exceeds the permitted use, you will need to obtain permission directly from the copyright holder. To view a copy of this licence, visit http://creativecommons.org/licenses/by/4.0/. 


\section{Introduction}

Rice blast is an acute, destructive disease that can reduce yields or even ruin an entire harvest. Grain blast also affects the quality of rice and poses a serious problem for food safety (Deng et al., 2017; Ishihara et al., 2014). In China, the disease affects more than 3.8 million hectares per year, reducing rice yield by 1 billion $\mathrm{kg}$ annually (Jiang et al., 2015; Tian et al., 2016). Rice blast, which is caused by the fungus $M$. oryzae, is the most devastating disease affecting rice under high temperature and humidity conditions, which favor its spread (Shen et al., 2004; Wang et al., 2017). Rice blast has been reported in almost all rice-producing areas worldwide, including the main rice-producing areas of 85 countries and regions (Miah et al., 2013; (Ballini et al, 2008).

Effective host resistance, conferred by resistance (R) genes, is considered to be the most economical approach to control plant diseases (Xiao et al., 2017; Wang \& Valent, 2017). To date, more than 100 rice-blast $\mathrm{R}$ genes have been isolated (Hua et al., 2012; Zhao et al., 2018). Although analyzing these genes has advanced our understanding of the molecular mechanisms underlying disease resistance, maintaining genetic resistance in rice is challenging because single rice varieties are grown over large areas in monoculture and the pathogen evolves quickly. $M$. oryzae is known for its genetic instability and pathogenic variability, leading to rapid breakdown of resistance in rice varieties (Bryan et al., 2000; Jiang et al., 2012). Resistant rice varieties often remain effective for only a few years before new dominant pathogenic races of the fungus emerge (Lee et al., 2009; Li et al., 2017).

Plants have evolved various mechanisms that protect them from pathogen invasion and colonization. $\mathrm{R}$ genes encode receptors containing a nucleotide-binding site and leucine-rich repeats (NBS-LRR). Most $\mathrm{R}$ genes are organized into tight clusters containing multiple gene copies. Nine of the 13 major rice blast R-genes are clustered (Qu et al., 2006; Wu et al., 2012) and most are broad-spectrum $\mathrm{R}$ genes with variable resistance. The tandem-repeat region of the Pi2/Pi9 locus contains at least six known R genes (Pi2, Pi9, Piz-t, Piz, Pigm, and $\mathrm{Pi50}$ ) and is situated close to the centromere of chromosome 6. Four $\mathrm{R}$ genes have been cloned in these regions (Dai et al. 2010; Zhou et al., 2006), divided into Pi2 locus and Pi9 locus. The Pi2 locus includes the $\mathrm{R}$ genes Pi2, Pigm and Piz-t, whereas the Pi9 locus includes the Pi9 R gene (Xiao et al., 2017). Numerous studies have indicated that the clustered arrangement of $\mathrm{R}$ genes has contributed to the evolution of novel resistance specificities via gene conversion, recombination, or unequal crossing over (Ashikawa et al., 2008; Dai et al., 2010). Some NBSLRR gene homologs at the same locus exhibit a different evolutionary pattern. Genomic analysis of the Pi9 locus in various rice cultivars and wild rice lines has shown that the copy numbers and SNP genotypes of Pi9 homologs vary, pointing to the complex evolutionary history of this R-gene locus (Wu et al., 2012).

Here, to gain insight into the origin and evolution of this locus, and to identify alleles with broad-spectrum resistance for use in molecular breeding, we analyzed the genomic sequences of the tandem-repeat region in 361 blast-resistant rice varieties. These 361 varieties were selected from a collection of 1883 varieties grown throughout China and were resistant to rice blast in at least one rice planting area. The tandem-repeat region of the Pi2/Pi9 locus contains at least four $\mathrm{R}$ genes that have been cloned (Pi2, Pi9, Piz-t and Pigm) (Dai et al. 2010; Zhou et al., 2006). The Pi2/Pi9 locus includes Pi2, Pigm, Piz-t, and the Pi9 locus includes Pi9 (Xiao et al., 2017). We reasoned these two loci might be functional sites for blast-resistance. Since we observed no alleles at the Pi2 locus aside from the previously the cloned genes Pi2, Pigm, and Piz-t, we focused on the Pi9 alleles, as this locus is a functional site that could represent the characteristics of these tandem-repeat regions.

We identified 13 novel Pi9 alleles (including the three types of Pi9-Type 5 alleles) in these 361 resistant rice varieties. We sequenced varieties carrying the novel alleles and compared them with the referenced sequence of Pi9 gene, concluding that 13 alleles were novel. We inoculated varieties carrying the novel alleles with $M$. oryzae and observed that the Pi9-Type3/4/5/6/9/10/11 alleles conferred broad-spectrum rice-blast-resistance. The identification of these novel alleles broadens our knowledge on Pi9-like gene family and enriches the genetic resources available for rice blast-resistance breeding and for research into the molecular mechanisms underlying rice-blast interactions. We constructed NILs containing the novel Pi9-Type3/4/5/6/9/10/11 alleles to exclude the interference of the $\mathrm{R}$ genes at other sites. The NILs harboring the individual Pi9-Type3/4/5/6/9/ $10 / 11$ alleles all showed resistance to rice-blast diseases in field trials in Enshi and Yichang, suggesting that these seven novel Pi9 alleles might account for the genetic variation in rice-blast-resistance. We plan to introduce these novel broad-spectrum resistance alleles into highquality rice varieties by molecular breeding to develop elite rice varieties with enhanced blast-resistance.

\section{Materials and Methods \\ Plant Materials}

Approximately 1883 rice cultivars, including indica and japonica types, were obtained from major rice-growing provinces in China and then maintained at Huazhong Agricultural University. Rice blast-resistant varieties were identified through natural inducement in two uniform rice-blast nurseries located at Enshi and Yichang 
in Hubei province. For each plant, the most seriously infected leaf was scored for each plant, as determined by using the HR-HS (HR-R-MR-MS-S-HS) scale rating system (Zhou et al., 2018), in which scores of HR-MR indicate an incompatible (resistant) reaction and scores of MS-HS indicate a compatible (susceptible) reaction,varieties that were resistant to field mix-inoculum were selected for molecular screening. Lijiangxin Tuan Heigu (LTH), which is highly susceptible to rice blast, was used as a control for disease evaluation.

\section{Pathogen Collection, Inoculation and Disease Evaluation}

For resistance spectrum analysis, we used 34 blast isolates of different races and virulence levels. These isolates, which were collected from across the major rice-growing provinces of China, are genetically distinct and belong to different blast lineages (Shen et al. 2004; Sasaki, 1922). We used these isolates to analyze phenotypes of parents with disease resistance genes. The $34 M$. oryzae isolates, which are highly virulent on most of the rice lines, were also used for phenotypic analysis of the Pi9 allele. These $34 M$. oryzae isolates were sequenced and analyzed for AvrPi9 and AvrPiz-t. The promoter and coding regions of AvrPi9 and AvrPiz- $t$ genes were sequenced and compared with reference sequences. The sequencing primers used are shown in Table S6.

Twelve-day-old seedlings were spray-inoculated with blast spore suspensions (approximately $1 \times 10^{5}$ spores/ $\mathrm{mL})$ and grown in a dark chamber for $24 \mathrm{~h}\left(26^{\circ} \mathrm{C}, 90 \%\right.$ humidity). Subsequently, the growth conditions were changed to $12 \mathrm{~h}$ light $/ 12 \mathrm{~h}$ of darkness. At 7 days post inoculation, the disease reaction (0-9 disease rating scale) of each line was recorded (IRRI, 2002).

\section{PCR for Allele Mining and Blast-Resistance Genes}

The tandem-repeat region of the Pi2/Pi9 locus contains two functional loci, Pi9 and Pi2 (including Pi2, Pigm and Piz- $t$ ). The BAC clone sequence of $O$. sativa $\mathrm{cv}$. 75-1127 (DQ285630.1, containing Pi9) was used as the Pi9 locus referenced sequence, and the genomic sequences of $O$. sativa cv. Nipponbare (www.ncbi.nlm.nih.gov), MH63 and ZS97 (http://rice.hzau.edu.cn/cgi-bin/rice2/ blast) varieties were used as the negative referenced sequences. RiceVarMap v2.0 (http://ricevarmap.ncpgr.cn/ wwwblast/blast1.html) was used to design PCR primers for the Pi9 alleles (Zhao et al., 2015) so that the primers could only amplify the functional Pi9 orthologues in resistant varieties and could not produce amplification PCR products from the negative reference varieties. Three pairs primers with successful amplification and covering the full-length $P i 9$ except for a gap region in intron1 were used for the Pi9 alleles. The primer designed at the Pi2 locus was similar to that of the Pi9 locus. The BAC clone sequences of O. sativa cv. GM4H (KU904633.2, containing Pigm) and C101A51 (DQ454158.1, containing Pi2) and O. sativa cv. ZY1H (DQ352040, containing Piz-t $t$ ) were used as referenced sequences for the Pi2 locus. The primers for amplification or sequnencing are given in Table S1.

Alleles were PCR amplified using genomic DNA extracted from rice leaves using the CTAB method (Murray and Thompson 1980). The $50 \mu \mathrm{L}$ reaction mix used for PCR included $50 \mathrm{ng}$ of template DNA, $0.2 \mu \mathrm{M}$ of both forward and reverse primers, $5 \mu \mathrm{L} 10 \times \mathrm{LA}$ Taq Buffer II, $8 \mu \mathrm{L}$ dNTP Mixture (2.5 mM each), and $2.5 \mathrm{U}$ TaKaRa LA Taq (RR02MQ, TAKARA). The primer sequences are listed in Table S1. Amplified PCR products were purified and sequenced using a Sanger's method-based ABI 3730XL DNA Analyzer Sequencer (ABI, Applied Biosystems Amersham, USA). Three PCR amplifications were performed per fragment, and each PCR product was sequenced. When the three sequencing results were consistent, the sequence information was utilized. Otherwise, PCR amplification and sequencing were repeated.

\section{DNA Sequence Analysis}

All the sequence reads generated for each allele by sequencing primers were assembled separately for each allele by using Sequencing Analysis Software Version 5.1 (Applied Biosystems). High-quality sequences were assembled, and the assembled DNA sequence of each allele was used to perform Blast2Sequences (https://blast. ncbi.nlm.nih.gov/Blast.cgi) analysis against the $P i 9$ genes to check its similarity.

SNPs and InDels were identified based on the Pi9 sequence as referenced sequences. For SNPs and InDels searches, multiple sequence alignment was performed for all alleles (along with Pi9 alleles from 75 to 1-127 as reference) using Sequencer's software. When analyzing genome sequence of the novel $P i 9$ alleles identified in this study, the gap region in intron 1 was replaced with the corresponding region of the reference $P i 9$ gene. Multiple sequence alignment of DNA sequences from amplified gene fragments and the referenced sequences (including $P i 9$, Pi2, Piz-t, Pigm, and all NBS disease resistance genes in this region) was performed using CLUSTALW (http://www.ebi. ac.uk/Tools/msa/clustalw2/) and MEGA5.0 (http://www. megasoftware.net) softwares. The parameters used for MEGA 5.0 were bootstrap (1000 replications) and neighbour joining with the p-distance model. A phylogenetic tree was constructed with MEGA to analysis the evolution of the $P i 9$ alleles. The average nucleotide diversity $(\pi)$, average nucleotide polymorphism $(\theta)$, and Tajima's D significance test values were used for calculating variation among all the alleles isolated from different varieties using DnaSP 5.0 software (Librado and Rozas 2009). Structural analyses of Pi9 
alleles were performed to predict protein structure and conserved domains using CDD software (https://www. ncbi.nlm.nih.gov/Structure/cdd/wrpsb.cgi), and the data were recorded as their position. Various domains, such as coiled-coil domain (CC), nucleotide-binding site (NBS), and leucine-rich repeats (LRR), which play vital roles in disease resistance, were shown on the protein sequences of all alleles using the customized R scripts.

\section{Crossing and Selection Scheme}

Plants harboring the Pi9 alleles were crossed with J23B, and the F1 hybrids were backcrossed with J23B to obtain the BC1F1 populations. Markers closely linked with the Pi9 resistance genes were used to check the corresponding Pi9 alleles in the above BC1F1 populations (Table S2). Six plants displaying closest phenotypic resemblance to J23B and including the target Pi9 allele from each BC1F1 populations were selected and their genetic backgrounds profiled using RICE6K (with 5102 SNP and InDel markers), a wholegenome SNP array (Yu et al. 2014). Only one plant with the target Pi9 allele and background closest to J23B was selected to backcross with $\mathrm{J} 23 \mathrm{~B}$ up to $\mathrm{BC} 2 \mathrm{~F} 1$ generation. Similarly, BC3F1 was obtained from BC2F1 populations by backcrossing the plant with the target gene and the background closest to J23B. After selfing, the $\mathrm{BC} 1 \mathrm{~F} 2, \mathrm{BC} 2 \mathrm{~F} 2$ and $\mathrm{BC} 3 \mathrm{~F} 2$ populations were obtained and used to evaluate the effects of individual Pi9 alleles in J23B backgrounds.

\section{Scoring Rice Blast-Resistance}

The BC3F2 families and control varieties were planted in a randomized complete block design in 2017 in Enshi and Yichang, Hubei Province, China. Enshi and Yichang are both mountainous areas with high humidity and heavy fog. The tests were performed in three replications. In each replication, each plot consisted of 4 rows with 6 plants per row at a planting density of $16 \mathrm{~cm}$ between plants and $16 \mathrm{~cm}$ between rows. To adequately induce blast disease infection, LTH was planted at both sides of each row and around the population. Field management essentially followed normal agricultural practices except that bactericides were not utilized.

All the plants were scored for leaf blast severity at the tillering stage and for neck blast severity at maturity stage using the HR-HS (HR-R-MR-MS-S-HS) scale rating system (IRRI, 2002; Zhou et al., 2018). The most seriously infected leaf among the top two or three new leaves was scored for each plant at the tillering stage as the leaf blast rate. The percentage of infection on the neck was scored for each plant at physiological maturity stage as neck blast rate.

\section{Results}

Selection of Rice Varieties for Pig Alleles Mining

We collected 1883 rice varieties originating from regions across China, including 729 farm-cultivated varieties, 485 varieties with core germplasm resources, 514 japonica varieties from northern China, and 155 varieties from other sources. To evaluate the blast-resistance of these varieties in regional trials, plants were grown at Enshi and Yichang, Hubei Province, where test nurseries have been established. We classified the disease resistance of the cultivars into six categories: HR (High Resistance) to HS (High Sensitivity). We identified 361 varieties that displayed HR or R phenotypes in Enshi or Yichang.

Four established broad-spectrum R-genes, Pigm, Pi2, $P i 9$ and Piz- $t$ are located in the same $\sim 10.38-\mathrm{Mb}$ region on the short arm of chromosome 6 . In the tandemrepeat region of the Pi2/Pi9 locus, two functional copies had been cloned in this tandem-repeat region: the Pi2 locus and Pi9 locus. The Pi2 locus, including Pi2, Pigm, and Piz-t, were specifically amplified from 55 of the 361 resistant varieties using the set of Pi2 primers (Table S1). No novel allele was identified at this locus; the only $\mathrm{R}$ genes present were the known genes Pi2, Pigm, and Piz-t. The Pi9 locus was specifically amplified from 108 of the 361 resistant varieties.

\section{Isolation of Pig Alleles}

Pi9 genomic sequences of approximately $8938 \mathrm{bp}$, including a parts of the promoters $(350 \mathrm{bp})$ and full-length coding regions $(8588 \mathrm{bp})$, were amplified and sequenced from 108 (one variety could not been sequenced) of the 361 resistant varieties. Based on our analysis of these sequences, we identified 13 novel Pi9 alleles from these 107 varieties (Table S3). The obtained sequences were compared with the reported $P i 9$ gene sequences, specifically in the coding region. The 13 alleles contained unique SNPs, insertions, and deletions. Figure 1a shows the sequence alignment of the novel Pi9 alleles.

The 13 novel $P i 9$ alleles were sequenced using sequencing primers for Pi2 (Pi2, Piz-t, and Pigm could be amplified with the same set of primers). Based on the sequencing results, Pi9-Type5 was divided into three types (donors of Pi9-Type5-Pi2, Pi9-Type5-Piz- $t$, and Pi9-Type5 carried Pi2, Piz-t, and no cloned genes, respectively). In addition, the donor of Pi9-Type4 carried the Pigm gene, and the donor of Pi9-Type8 carried the Piz-t gene (Table S3).

\section{Sequence Analysis of the Pig Alleles}

Among the 13 Pi9 alleles identified, Pi9-Type8 shared the lowest level of genomic sequence identity (92\%) with the reference allele $P i 9$, and seven alleles had more than 99\% identity (Pi9-Type1, Pi9-Type5, Pi9Type6, Pi9-Type8, Pi9-Type10, Pi9-Type12, and Pi9Type13) (Table 1). These 13 alleles differed from Pi9 by numerous nucleotide polymorphisms, insertions, and deletions that were either unique or shared among the different alleles. 


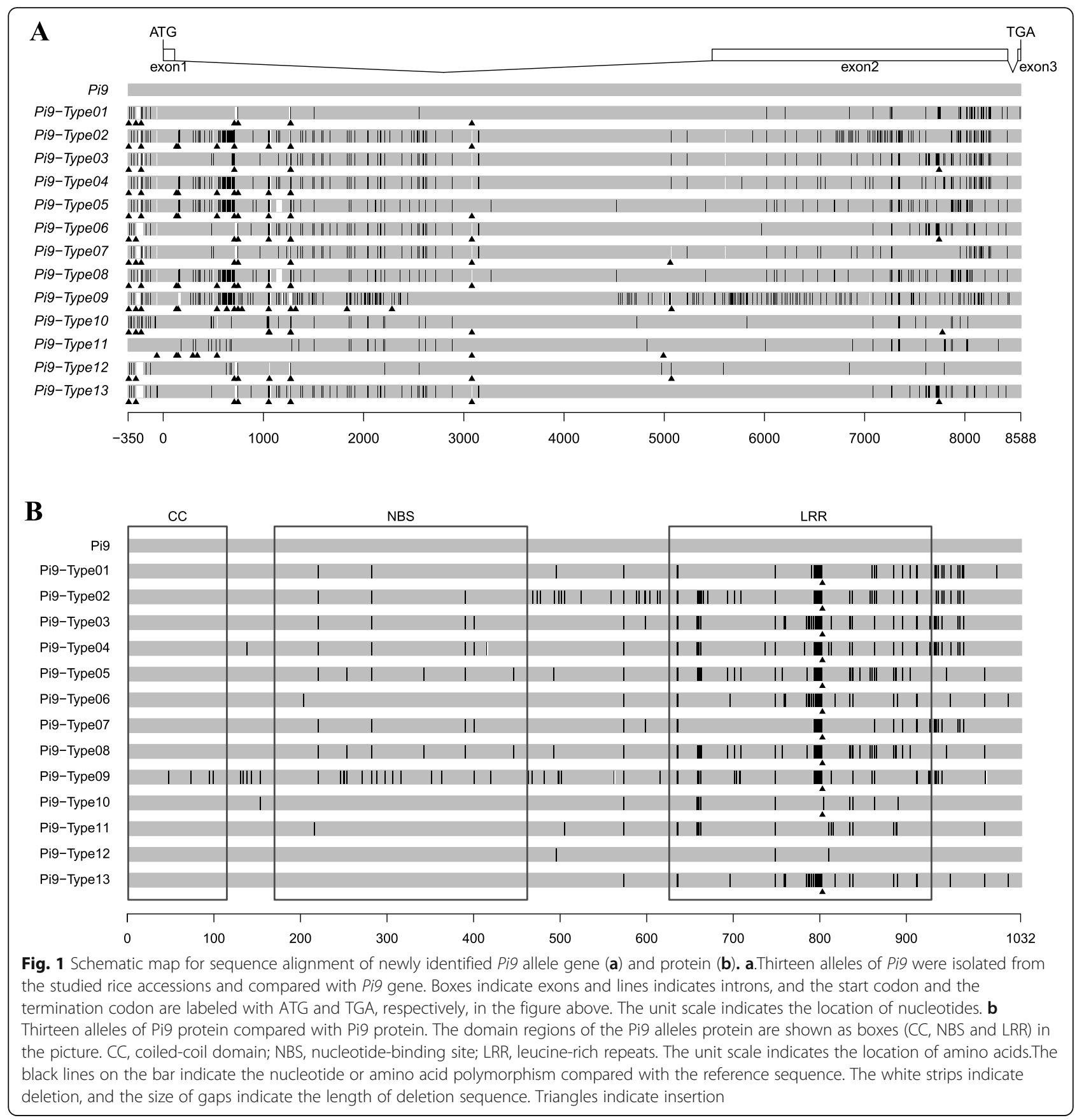

The alleles include two large insertions/deletions in the nucleotide sequence between -350 and $0 \mathrm{bp}$ (considering the start codon as $0 \mathrm{bp}$ ) (Fig. 1b; Table S3). Pi9Type11 has a 515-bp insertion at - 274 bp and a unique 232-bp insertion at -64 bp (Fig. 1b; Table S4). In the first intron of the $P i 9$, we identified three large insertions located at + 150 bp (a 366-bp insertion), + 714 bp (a 126bp insertion), and +2290 bp (a 48-bp insertion). The insertion at $+150 \mathrm{bp}$ was present in Pi9-Type $2 / 4 / 5 / 8 / 9$ and that at $+714 \mathrm{bp}$ was present in Pi9-Type2/4/5/8
(Fig. 1b; Table S3). The insertion at +2290 bp was only present in Pi9-Type9.

All $P i 9$ alleles have conserved sequences in the CC and NBS domains, suggesting that these domains are important for Pi9 function. By contrast, in the LRR domain, the sequence of these alleles were highly polymorphic. The allelic variation in the LRR domain indicates that this region is under less selective pressure than the other domains (Fig. 2; Table 2). We also performed nucleotide polymorphism analyses for all $13 \mathrm{Pi} 9$ 
Table 1 Summary of SNP and different alleles of the Pig gene in different species

\begin{tabular}{|c|c|c|c|c|c|c|c|c|c|c|c|}
\hline \multirow[t]{2}{*}{ Pi9 allele } & \multirow[t]{2}{*}{ Varieties } & \multirow{2}{*}{$\begin{array}{l}\text { Number of } \\
\text { accessions } \\
\text { carrying } \\
\text { the allele }\end{array}$} & \multirow{2}{*}{$\begin{array}{l}\text { Identity } \\
\text { to Pig }\end{array}$} & \multirow{2}{*}{$\begin{array}{l}\text { Number } \\
\text { of SNP } \\
\text { sites }\end{array}$} & \multicolumn{3}{|c|}{ Number of SNP sites } & \multirow{2}{*}{$\begin{array}{l}\text { Number of } \\
\text { inserts/ } \\
\text { deletions }\end{array}$} & \multicolumn{3}{|c|}{ Number of inserts/deletions } \\
\hline & & & & & $\mathrm{Pt}$ & Ex & In & & $\mathrm{Pt}$ & Ex & In \\
\hline Pi9 & $75-1-127$ & 2 & - & - & - & - & - & - & - & - & - \\
\hline Pi9-Type1 & Heo Trang & 1 & $99 \%$ & 79 & 29 & 47 & 3 & 17 & 9 & 0 & 8 \\
\hline Pi9-Type2 & IR64 & 2 & $95 \%$ & 443 & 246 & 94 & 103 & 259 & 10 & 0 & 249 \\
\hline Pi9-Type3 & $\mathrm{HC} 1 \mathrm{H}$ & 13 & $98 \%$ & 134 & 33 & 61 & 40 & 26 & 20 & 3 & 3 \\
\hline Pi9-Type4 a & PIIB & 11 & $96 \%$ & 410 & 253 & 56 & 101 & 266 & 10 & 0 & 256 \\
\hline Pi9-Type5 a & XS209 & 56 & $95 \%$ & 451 & 259 & 57 & 135 & 320 & 9 & 0 & 311 \\
\hline Pi9-Тyре6 & YD4038 & 1 & $99 \%$ & 104 & 25 & 31 & 48 & 241 & 9 & 3 & 12 \\
\hline Pi9-Type7 & KAUKKYI ANI & 2 & $99 \%$ & 105 & 30 & 36 & 39 & 23 & 20 & 0 & 3 \\
\hline Pi9-Type8 a & DY1H & 6 & $92 \%$ & 710 & 519 & 56 & 135 & 581 & 9 & 0 & 572 \\
\hline Pi9-Тyре9 & THAVALU & 1 & $93 \%$ & 608 & 312 & 103 & 193 & 342 & 109 & 3 & 230 \\
\hline Pi9-Type10 & ZWH210 & 6 & $97 \%$ & 316 & 282 & 16 & 18 & 269 & 259 & 0 & 10 \\
\hline Pi9-Type11 & R03138 & 3 & $96 \%$ & 387 & 339 & 22 & 26 & 339 & 234 & 0 & 105 \\
\hline Pi9-Type12 & $J P-5$ & 1 & $99 \%$ & 32 & 22 & 4 & 6 & 9 & 7 & 0 & 2 \\
\hline Pi9-Type13 & $\mathrm{ZD} 5 \mathrm{H}$ & 2 & $99 \%$ & 105 & 26 & 30 & 49 & 26 & 9 & 3 & 14 \\
\hline
\end{tabular}

a Pigm is contained in the donor of Pi9-Type4; Piz-t is contained in the donor of Pi9-Type8 and a part of Pi9-Type5; Pi2 is contained in the donor of a part of Pig-Type5

Pt Promoter; Ex Exon; In Intron. Varieties, Representative donor variety containing the allele

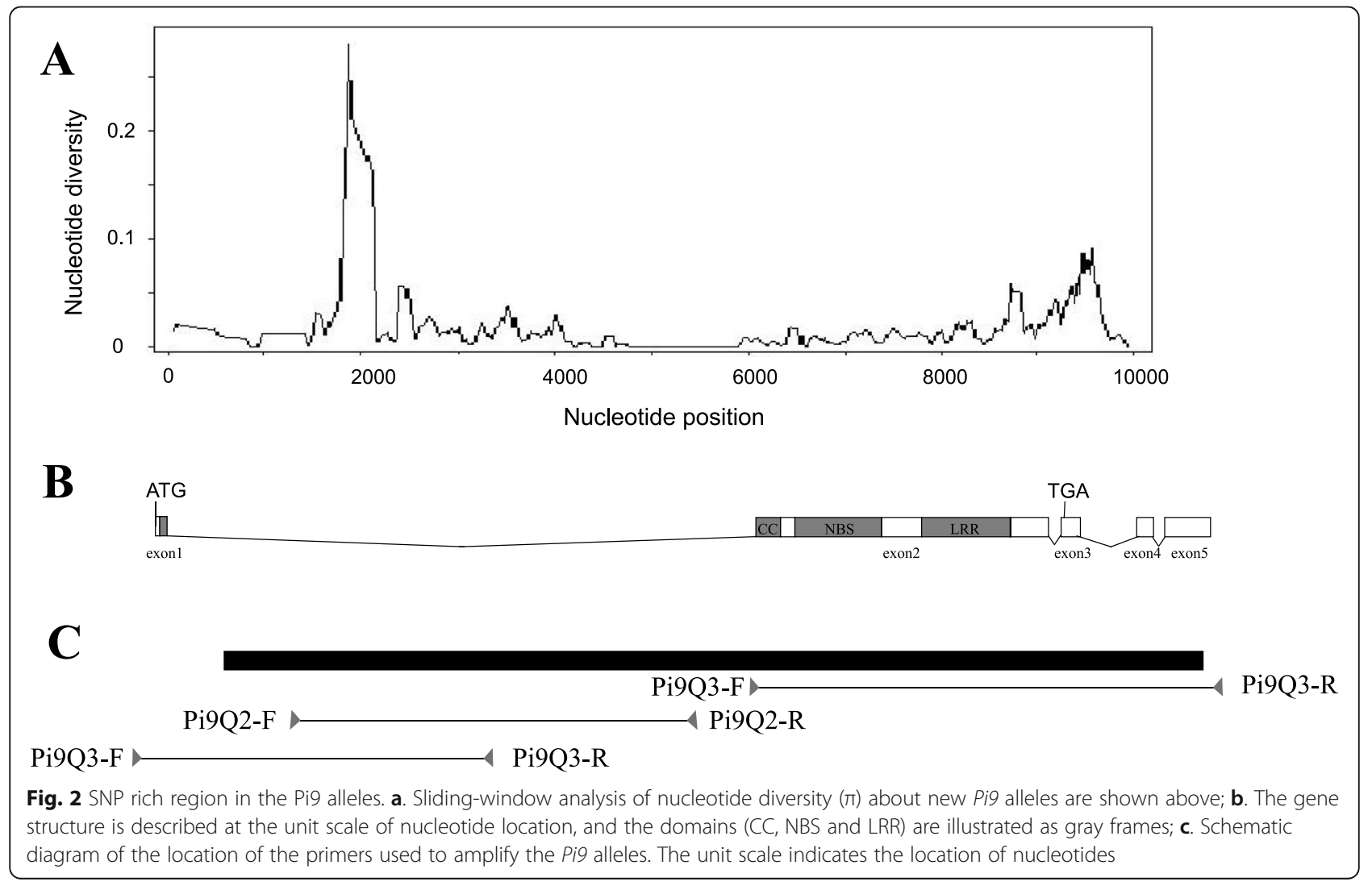


Table 2 Summary of the natural variation of different Pi9 allele genes in different species

\begin{tabular}{llll}
\hline Region & $\boldsymbol{\pi}$ & $\boldsymbol{\theta}$ & Tajima's D \\
\hline CC & 0.00670 & 0.01475 & -2.23881 \\
NBS & 0.01035 & 0.01574 & -1.49472 \\
LRR & 0.03311 & 0.03529 & -0.27483 \\
Promoter & 0.01401 & 0.01823 & -0.94844 \\
Exon1 & 0 & 0 & - \\
Intron1 & 0.01499 & 0.01665 & -0.45014 \\
Exon2 & 0.02137 & 0.02604 & -0.80967 \\
Intron2 & 0 & 0 & - \\
Exon3 & 0 & 0 & - \\
\hline
\end{tabular}

Nucleotide diversity $(\pi)$, Watterson's Theta $(\theta)$, and Tajima's D for alleles CC Coiled-coil domain; NBS Nucleotide-binding site; LRR Leucine-rich repeats

alleles using DnaSP5.10. The average nucleotide diversity $(\pi)$ of the alleles was 0.01674 . Sliding-window analysis of $P i 9$ nucleotide diversity in the Pi9 allele showed that the diversity rate was higher in regions with abundant nucleotide polymorphisms and that there were more deletions/insertions in the first intron than elsewhere in the allele (Fig. 2; Table 2). The Tajima D test value was less than 1 (-0.64099), indicating that the Pi9 locus is under positive selection, especially in the conserved CC and NBS domains (Fig. 2; Table 2).

\section{Analysis of the Deduced Pi9 Protein Sequences}

$\mathrm{Pi} 9$ proteins are composed of three conserved domains: CC, NBS, and LRR. All of the newly identified alleles have complete open reading frames (ORFs) similar to that of Pi9 (Fig. 1b; Table 3; Table S4). The alleles' predicted encoded protein had high similarity with the control Pi9 protein sequence (94.0-99.7\%), with the alleles containing complete CC-NBS-LRR domains. Of all the allele amino acid sequences, Pi9-Type9 had the most amino acid differences compared to the Pi9 amino acid sequence. In the CC domain, only Pi9-Type9 had amino acid differences ( 4 amino acids are different from the Pi9 amino acid sequence). In the NBS domain, there were no difference between Pi9-Type10/12/13 and Pi9 proteins. In the LRR region, there were more differences between the proteins predicted to be encoded by each allele type, of which Pi9-Type5/8 had the most differences, with 27 amino acid differences. Pi9-Type12 had the fewest differences, with only 2 amino acid differences. None of the $13 \mathrm{Pi} 9$ allele proteins had amino acid insertions/deletions in the CC and NBS domains, and only one amino acid insertion was detected in the LRR domain in Pi9-Type1 10/13 (Table 3, Table S5).

\section{Phylogeny and Distribution of the Novel Pig Alleles}

In addition to the cloned Pi9 gene, we identified 13 Pi9 alleles in this chromosomal region. The reference allele $P i 9$ is derived from the 75-1-127 donor. The presence of other $P i 9$ alleles varied among rice varieties. Four of the 13 novel Pi9 alleles (i.e., Pi9-Type1, Pi9-Type6, Pi9Type9, and Pi9-Type12) were present in only one rice line each. Pi9-Type2, Pi9-Type7, Pi9-Type11, and Pi9Type13 were present in fewer than three varieties. The remaining alleles were present in more than six varieties

Table 3 Summary of difference in each alleles of the Pi9 protein

\begin{tabular}{|c|c|c|c|c|c|c|c|c|c|c|c|}
\hline \multirow[t]{2}{*}{ Protein } & \multirow[t]{2}{*}{ Varieties } & \multirow{2}{*}{$\begin{array}{l}\text { AA } \\
\text { Number }\end{array}$} & \multirow{2}{*}{$\begin{array}{l}\text { Identity } \\
\text { to Pi9 }\end{array}$} & \multirow{2}{*}{$\begin{array}{l}\text { Number } \\
\text { of SNP } \\
\text { sites }\end{array}$} & \multicolumn{3}{|c|}{ Number of SNP sites } & \multirow{2}{*}{$\begin{array}{l}\text { Number of } \\
\text { inserts/ } \\
\text { deletions }\end{array}$} & \multicolumn{3}{|c|}{ Number of inserts/deletions } \\
\hline & & & & & CC & NBS & LRR & & CC & NBS & LRR \\
\hline Pi9 & $75-1-127$ & 1032 & - & - & - & - & - & - & - & - & - \\
\hline Pi9-Type1 & Heo Trang & 1032 & $97.0 \%$ & 31 & 0 & 2 & 15 & 3 & 0 & 0 & 1 \\
\hline Pi9-Тyре2 & IR64 & 1033 & $95.0 \%$ & 52 & 0 & 3 & 23 & 3 & 0 & 0 & 1 \\
\hline Pi9-Type3 & $\mathrm{HC} 1 \mathrm{H}$ & 1031 & $95.9 \%$ & 40 & 0 & 4 & 26 & 3 & 0 & 0 & 1 \\
\hline Pi9-Type4 & PIIB & 1032 & $96.3 \%$ & 36 & 0 & 5 & 18 & 2 & 0 & 0 & 1 \\
\hline Pi9-Type5 & XS209 & 1033 & $96.4 \%$ & 37 & 0 & 6 & 27 & 3 & 0 & 0 & 1 \\
\hline Pi9-Туре6 & YD4038 & 1032 & $97.4 \%$ & 25 & 0 & 1 & 20 & 2 & 0 & 0 & 1 \\
\hline Pi9-Type7 & KAUKKYI ANI & 1032 & $97.9 \%$ & 22 & 0 & 4 & 8 & 2 & 0 & 0 & 1 \\
\hline Pi9-Тyре8 & DY1H & 1030 & $96.4 \%$ & 37 & 0 & 6 & 27 & 2 & 0 & 0 & 1 \\
\hline Pi9-Тype9 & THAVALU & 1033 & $94.0 \%$ & 58 & 4 & 15 & 19 & 3 & 0 & 0 & 1 \\
\hline Pi9-Type10 & ZWH210 & 1032 & $98.6 \%$ & 12 & 0 & 0 & 10 & 2 & 0 & 0 & 1 \\
\hline Pi9-Type11 & R03138 & 1032 & $98.2 \%$ & 19 & 0 & 1 & 15 & 0 & 0 & 0 & 0 \\
\hline Pi9-Type12 & $J P-5$ & 1033 & $99.7 \%$ & 3 & 0 & 0 & 2 & 1 & 0 & 0 & 0 \\
\hline Pi9-Тype13 & $\mathrm{ZD} 5 \mathrm{H}$ & 1032 & $97.5 \%$ & 24 & 0 & 0 & 20 & 3 & 0 & 0 & 1 \\
\hline
\end{tabular}

Varieties, Representative donor variety containing the alleles; AA Number Number of amino acids in Pi9 allele proteins; CC Coiled-coil domain; NBS Nucleotidebinding site; $L R R$ Leucine-rich repeats 
(Table 1). Among the Pi9 alleles, Pi9-Type5 was the most widespread and was detected in 56 varieties.

The phylogeny of Pi9 alleles was analyzed after adding the sequences of Pi9, Pi2, Piz-t, Pigm and all NBS disease resistance genes at the tandem-repeat region of the Pi2/Pi9 locus. The NBS genes in BAC clones Pi9 (DQ285630), Pi2 (DQ352453), Pigm (KU904633), Piz(DQ352040), and others (GQ280265, GQ280266, GQ280267, GQ280268, GQ280269, DQ454158) from the NCBI database were used for the phylogenetic analysis. A phylogenetic tree was constructed using nucleotide sequences that included the complete ORF and $350 \mathrm{bp}$ of the promoter sequence upstream of the start codon or the predicted protein sequences. Phylogenetic analysis of gDNA indicated that the Pi9 homologues in these varieties were more closely related to each other than to the other homologues (Fig. 3). The results obtained using genomic and protein sequences differed substantially: Pi9 alleles that encode similar protein sequences did not show higher genomic sequence similarity (Fig. 3a and Fig. 3b). However, Pi9-Type6/13 and Pi9-Type5/8 showed very high genomic and protein sequence similarity (Fig. 3).

\section{Evaluation of Blast-Resistance Using Different M. oryzae Isolates}

About 34 M. oryzae isolates from Hubei, Jiangxi, Hunan, Fujian, and Guangdong Provinces, China, were sequenced and analyzed for AvrPi9 and AvrPiz-t. All 34 M. oryzae isolates contained AvrPi9, and about half of them contained the AvrPiz- $t$ gene. We assessed the leaf blastresistance of the 13 alleles of Pi9 donors and their Pigm, Pi2, Pi9, and Piz-t donors in the greenhouse using these $34 \mathrm{M}$. oryzae isolates. The donors of Pigm, Pi2, Pi9, and Piz-t, i.e., Gumei4, C101A51, 75-1-127, and DY1H, respectively, showed broad-spectrum resistance to rice blast with resistance frequencies ranging from 58.8 to 94.1\%. Since the collected $M$. oryzae isolates all contained AvrPi9 (Table S7), the donors of Pi9 showed the best broad-spectrum resistance of $94.1 \%$. The resistance frequencies of donors of the Pi9 allele ranged from 23.5 to $100 \%$. The donor GD-1S (containing the Pi9-Type 5 allele) and the donor THAVALU (containing the Pi9Type9 allele) were resistant to all 34 blast isolates, with a resistance frequency of $100 \%$, an even higher resistance frequency than GM4H. The donors YD4038 and ZWH210, containing the Pi9-Type6 and Pi9-Type10 alleles, were resistant to more than 30 of 34 blast isolates with a resistance frequency of more than $91.2 \%$ (Table 4). The blast-resistance evaluation scale was used to evaluate leaf blast from 0 to 9 according to IRRI standard for each blast isolates, and the resistance level was calculated as average with 34 blast isolates infection for each varieties. The resistance level of donors of the Pi9 allele ranged from 1.79 to 5.62 , and there was also a correlation between resistance ratio and resistance level. When the resistance ratio was higher than $85 \%$, the resistance level was usually less than 3 . The varieties with a resistance ratio greater than $85 \%$ and a resistance value less than 2 were chosen as broad-spectrum resistant varieties to been used to construct the NILs.

\section{Construction of the NILs and Evaluation of Blast- Resistance in Field Trials}

In order to choose the ideal donor for rice blast breeding and characterize the novel $\mathrm{Pi} 9$ alleles function, seven $\mathrm{Pi} 9$ allele genes with a resistance ratio of $>85 \%$ (Pi9-Type3, Pi9-Type4, Pi9-Type5, Pi9-Type6, Pi9-Type9, Pi9Type10, and Pi9-Type11) and four cloned genes (Pigm, Pi2, Pi9 and Piz-t) were introduced into the recurrent parent J23B to construct NILs. For the NILs construction, different donors were crossed to J23B and the F1 hybrids were backcrossed with J23B to obtain the BC1F1 population, then from the $\mathrm{BC} 1 \mathrm{~F} 1$ population we selected six plants displaying closest phenotypic resemblance to J23B and containing the Pi2/Pi9 locus with markers selection to profile using our RICE6K array, then we selected one plant with the target Pi9 allele gene and a background closest to J23B and without any region containing the known rice blast genes, to backcross with J23B up to BC3F1. After three consecutive rounds of selection, the chip data for BC3F1 showed that the background of the NILs was more than $85 \%$ similar to J23B, and these newly developed NILs included the whole tandem-repeat region of the Pi2/Pi9 locus, but no other known resistance tandem-repeat regions, such as the Pik locus on Chr. 11 and the Pi3/Pi5 locus on Chr. 9. We examined the resistance of the seven alleles and four cloned genes in both the J23B and donor parents' background to leaf blast and neck blast at Enshi and Yichang in 2017.

Among the four cloned genes, Pigm conferred the greatest resistance to both leaf blast and neck blast in the J23B or donor parent background at both Enshi and Yichang (Table 5). Like the cloned genes, among the seven Pi9 allele genes, Pi9-Type6, Pi9-Type10, and Pi9Type11 showed significantly enhanced resistance to leaf blast and neck blast in the J23B background compared with the control J23B at both Enshi and Yichang (Table 5). Pi9-Type3, Pi9-Type5, and Pi9-Type9 significantly enhanced resistance to leaf blast at Enshi (Table 5). Pi9Type3 also significantly enhanced resistance to neck blast at Enshi and Yichang, but Pi9-Type5 and Pi9Type9 conferred enhanced resistance to neck blast only in Yichang. All of the Pi9 alleles conferred enhanced resistance to leaf or neck blast in at least one location. Moreover, Pi9-Type6 and Pi9-Type11 were associated with greater resistance to both leaf blast and neck blast than the cloned genes Pi2 and Piz-t (Table 5). 


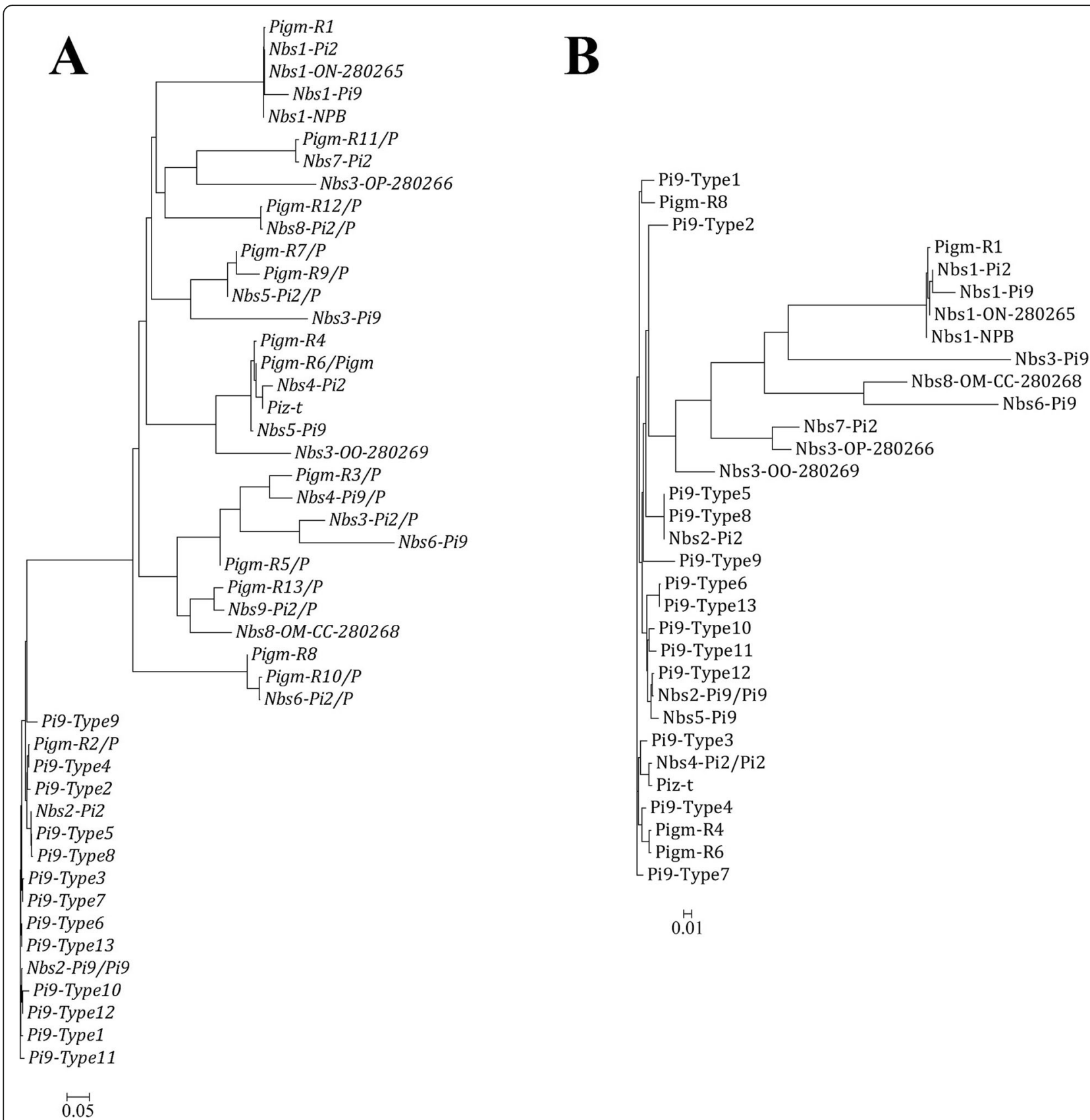

Fig. 3 Phylogenetic relationship among gDNA and protein sequences of NBS genes at Pi2/9 locus. Thirteen new Pi9 allele sequences found in our research materials and the sequences of Pi9, Pi2, Piz-t, Pigm, and all NBS disease resistance genes at the tandem repeat region of the Pi2/Pi9 locus were used for analysis. a. Phylogenetic tree of the genomic sequences (from ATG to TGA, including the introns) for 13 novel Pi9 alleles based on our sequencing results and NBS genes at Pi2/9 locus; b. Phylogenetic tree of the protein sequences of 13 novel Pi9 alleles protein and NBS proteins at Pi2/9 locus. Bootstrap values (1000 replications) are mentioned at the branch nodes

\section{Discussion}

\section{Current Status of Cloning and Characterization of Rice Blast R-Genes}

Identifying and cloning novel broad-spectrum blast Rgenes is critical for breeding resistant rice varieties and has been a major focus of rice genome research. With the development of molecular marker technology, the construction of a high-density genetic linkage map, and the improvement of related molecular techniques, great progress has been made in cloning rice blast R-genes (Chen et al., 2006; Hayashi and Yoshida, 2009; Hittalmai et al., 2000; Lin et al., 2007; Sharma et al., 2005).

The theory of rice blast-resistance genes was first presented by Sasaki in 1922, initiating nearly 100 years 
Table 4 Disease responses of Pigm, Pi2, Pizt, Pi9 and Pi9 alleles honor plants to M. oryzae isolates

\begin{tabular}{|c|c|c|c|}
\hline Gene & Varieties & Resistance ratio & Resistance level \\
\hline None & LTH & $0.00 \%$ & $8.15 \pm 0.77$ \\
\hline None & $J 23 B$ & $0.00 \%$ & $6.22 \pm 1.19$ \\
\hline Pigm & GM4H & $91.20 \%$ & $2.43 \pm 1.82$ \\
\hline Pi2 & C101 A51 & $67.60 \%$ & $3.81 \pm 1.84$ \\
\hline Pi9 & $75-1-127$ & $94.10 \%$ & $2.71 \pm 1.14$ \\
\hline Pizt & DY1H & $58.80 \%$ & $4.16 \pm 2.70$ \\
\hline Pi9-Type1 & Heo Trang & $26.50 \%$ & $5.10 \pm 2.14$ \\
\hline Pi9-Type2 & IR64 & $23.50 \%$ & $5.62 \pm 1.70$ \\
\hline Pi9-Tyре3 a & $\mathrm{HC} 1 \mathrm{H}$ & $85.30 \%$ & $2.88 \pm 2.09$ \\
\hline Pig-Type4 a & PIIB & $88.20 \%$ & $2.01 \pm 1.31$ \\
\hline Pig-Type5 a & GD-1S & $100.00 \%$ & $1.79 \pm 0.72$ \\
\hline Pi9-Type5-Pi2 & CT 18664-9-18-1-3-2 & $70.60 \%$ & $3.15 \pm 2.00$ \\
\hline Pi9-Type5-Piz-t & ASD 18 & $67.60 \%$ & $3.56 \pm 1.76$ \\
\hline Pig-Type6 ${ }^{\text {a }}$ & YD4038 & $91.20 \%$ & $2.03 \pm 1.25$ \\
\hline Pi9-Type7 & KAUKKYI ANI & $61.80 \%$ & $4.04 \pm 2.45$ \\
\hline Pi9-Type8 & DY1H & $58.80 \%$ & $4.16 \pm 2.70$ \\
\hline Pi9-Type9 a & THAVALU & $100.00 \%$ & $1.79 \pm 0.72$ \\
\hline Pi9-Type10 a & ZWH210 & $94.10 \%$ & $2.07 \pm 1.59$ \\
\hline Pig-Type11 a & R03138 & $88.20 \%$ & $2.75 \pm 1.58$ \\
\hline Pi9-Type12 & $J P-5$ & $79.40 \%$ & $2.72 \pm 1.64$ \\
\hline Pig-Type13 & $\mathrm{ZD} 5 \mathrm{H}$ & $55.90 \%$ & $4.43 \pm 2.36$ \\
\hline
\end{tabular}

${ }^{a}$ When Resistance ratio was greater than $85 \%$ and Resistance level was less than 2 , NILs of allele materials were done

Resistance ratio, the proportion above MR inoculated with $34 \mathrm{M}$. oryzae isolates; Resistance level, the average level inoculated with $34 \mathrm{M}$. oryzae isolates. None, no functional Pi9 allele; Pi9-Type5 has three different type Pi9-Type5, Pi9-Type5-Pi2 and Pi9-Type5-Piz-t. Donors of Pi9-Type5-Pi2 and Pi9-Type5-Piz-t carried Pi2 and Piz-t genes, respectively. Donors of Pi9-Type4 carried Pigm. Donors of Pi9-Type8 carried Piz- $t$

of discovery and utilization of these genes in rice breeding (Sasaki et al., 1922). In 1966, Yamasaki cloned the rice blast R-genes Pia, Pii, and Pik (Yamasaki and Kiyosawa, 1966) from Aichi Asahi, Ishikari Shiroke, and Kanto 51. In 1999, Wang cloned the R-gene Pib (Wang et al., 1999) by map-based cloning. With improvements in technology, the cloning and exploitation of rice-blast $\mathrm{R}$ genes has seen tremendous progress in the twentyfirst century. To date, 119 blast R-genes and more than 400 quantitative trait loci (QTLs) have been mapped, and more than 30 blast-resistance genes have been mapped and cloned (Balliniet et al., 2008; Bryan et al., 2000; Chen et al., 2018a; Chen et al., 2006; Chen et al., 2018b; Fukuoka et al., 2009; Inoue et al., 2017; Hayashi et al., 2010; Ishihara et al., 2014; Li et al., 2017; Lin et al., 2007; Liu et al., 2002; Liu et al., 2007; Zhao et al., 2018).

Most blast R-genes, except for a few genes such as pi21, Pid2, Pid3, and Ptr, encode nucleotide-binding site leucine-rich repeat (NBS-LRR) proteins (Chen et al., 2006; Fukuoka et al., 2009; Liu et al., 2007; Xu et al., 2014). Analysis of the cloned blast R-genes revealed that most of the broad-spectrum R-genes are located in tandemly repeated gene clusters on chromosomes 6,9 ,
11, and 12. Generally, rice blast genes that have an NBSLRR structure and occur in tandem repeat regions confer broad-spectrum resistance. The structures of tandem-repeat regions differ greatly among rice varieties, harboring various inversions and deletions. Furthermore, many R-genes with highly similar structures are tandemly duplicated with pseudogenes (Dai et al., 2010).

The short arm of chromosome 6 contains at least 10 blast R-genes (Pigm, Pi2, Pi9, Piz-t, Piz, Pi22, Pi25, Pi26, Pi40, and Pi42)), arranged as tandem repeats (Deng et al., 2006). Pi2, which was cloned from the variety 'C101 A51', encodes a 1032 amino acid NBS-LRR protein (Hittalmani et al., 2000; Zhou et al., 2006). Pi9 is highly similar to $P i 2$ but has a different resistance profile (Xiao et al., 2017). Piz-t, derived from Xiushui 209, differs from Pi2 at eight amino acids (Fig. 1) due to differences at more than 20 bases in the coding regions of the two genes. Pigm is an unusual R-gene formed by one copy each of PigmR and PigmS in series. PigmR imparts broad-spectrum disease resistance but reduces yield. PigmS does not confer resistance but improves seed setting rate. Here, we focused our analysis on this region of chromosome 6 due to its high density of $\mathrm{R}$ genes and 
Table 5 Disease responses of Pigm, Pi2, Pizt, Pi9 and Pi9 alleles honor plants to M. oryzae isolates

\begin{tabular}{|c|c|c|c|c|c|c|}
\hline \multirow[t]{2}{*}{ Gene } & \multirow[t]{2}{*}{ Varieties } & \multirow[t]{2}{*}{ Generation } & \multicolumn{2}{|c|}{ Enshi } & \multicolumn{2}{|c|}{ Yichang } \\
\hline & & & $\mathrm{Lr}$ & $\mathrm{Nr}$ & $\mathrm{Lr}$ & $\mathrm{Nr}$ \\
\hline None & LTH & FO & S & $\mathrm{S}$ & $\mathrm{HS}$ & $\mathrm{S}$ \\
\hline None & $J 23 B$ & F0 & MS & S & $\mathrm{HS}$ & MS \\
\hline Pigm & $\mathrm{GM} 4 \mathrm{H}$ & FO & $\mathrm{MR}$ & $\mathrm{R}$ & $H R$ & $H R$ \\
\hline Pi2 & C101 A51 & FO & $\mathrm{R}$ & MR & MR & MR \\
\hline Pi9 & $75-1-127$ & FO & $\mathrm{MR}$ & $\mathrm{R}$ & $H R$ & $\mathrm{R}$ \\
\hline Pizt & DY1H & F0 & $\mathrm{MR}$ & MR & $R$ & MR \\
\hline Pi9-Type1 & Heo Trang & FO & $H R$ & $\mathrm{R}$ & $\mathrm{HR}$ & $\mathrm{R}$ \\
\hline Pi9-Type2 & IR64 & F0 & MS & MS & $R$ & $\mathrm{R}$ \\
\hline Pig-Type3 ${ }^{\text {a }}$ & $\mathrm{HC} 1 \mathrm{H}$ & F0 & $\mathrm{R}$ & MR & $\mathrm{R}$ & R \\
\hline Pi9-Type4 ${ }^{\text {a }}$ & PIIB & F0 & R & $\mathrm{R}$ & $\mathrm{HR}$ & $H R$ \\
\hline Pig-Type5 a & GD-1S & FO & R & $\mathrm{HR}$ & $H R$ & $H R$ \\
\hline Pi9-Type5-Pi2 & CT 18664-9-18-1-3-2 & F0 & MR & MR & MR & $\mathrm{MR}$ \\
\hline Pi9-Type5-Pizt & ASD 18 & F0 & $\mathrm{MR}$ & MS & MR & MR \\
\hline Pi9-Type6 ${ }^{\text {a }}$ & YD4038 & F0 & R & $H R$ & $H R$ & $\mathrm{HR}$ \\
\hline Pi9-Type7 & KAUKKYI ANI & F0 & MR & $\mathrm{HR}$ & $\mathrm{HR}$ & $\mathrm{R}$ \\
\hline Pi9-Тyре8 & DY1H & F0 & S & $\mathrm{HS}$ & $\mathrm{HR}$ & $H R$ \\
\hline Pig-Type9 a & THAVALU & F0 & $\mathrm{HR}$ & $\mathrm{R}$ & $\mathrm{HR}$ & $\mathrm{R}$ \\
\hline Pi9-Type10 a & ZWH210 & F0 & $\mathrm{R}$ & $H R$ & $\mathrm{HR}$ & MR \\
\hline Pig-Type $11^{a}$ & R03138 & FO & $H R$ & $H R$ & $H R$ & $H R$ \\
\hline Pi9-Тype12 & $J P-5$ & F0 & $\mathrm{R}$ & $H R$ & $H R$ & MS \\
\hline Pi9-Type13 & ZD5H & F0 & $\mathrm{MR}$ & MR & $\mathrm{R}$ & $\mathrm{HS}$ \\
\hline Pigm & $\mathrm{GM} 4 \mathrm{H}$ & $\mathrm{BC} 3 \mathrm{~F} 2$ & $\mathrm{MR}$ & MR & $R$ & $H R$ \\
\hline Pi2 & C101 A51 & $\mathrm{BC} 2 \mathrm{~F} 2$ & $\mathrm{MR}$ & MS & MR & $\mathrm{R}$ \\
\hline Pi9 & $75-1-127$ & $\mathrm{BC} 3 \mathrm{~F} 2$ & $\mathrm{MR}$ & MR & R & R \\
\hline Pizt & DY1H & $\mathrm{BC} 3 \mathrm{~F} 2$ & $\mathrm{MR}$ & MS & MR & MR \\
\hline Pi9-Tyре3 & $\mathrm{HC} 1 \mathrm{H}$ & $\mathrm{BC} 3 \mathrm{~F} 2$ & $\mathrm{MR}$ & MR & MS & $\mathrm{R}$ \\
\hline Pi9-Type4 & PIIB & $\mathrm{BC} 2 \mathrm{~F} 2$ & $\mathrm{MR}$ & $\mathrm{R}$ & $H R$ & $\mathrm{R}$ \\
\hline Pi9-Type5 & GD-1S & $\mathrm{BC} 3 \mathrm{~F} 2$ & $\mathrm{MR}$ & MS & R & $\mathrm{R}$ \\
\hline Pi9-Type6 & YD4038 & $\mathrm{BC} 3 \mathrm{~F} 2$ & R & MR & R & $\mathrm{R}$ \\
\hline Pi9-Type9 & THAVALU & $\mathrm{BC} 3 \mathrm{~F} 2$ & $\mathrm{MR}$ & MS & R & MR \\
\hline Pi9-Type10 & ZWH210 & $\mathrm{BC} 2 \mathrm{~F} 2$ & R & MR & R & MR \\
\hline Pi9-Type11 & R03138 & $\mathrm{BC} 3 \mathrm{~F} 2$ & R & MR & R & $\mathrm{R}$ \\
\hline
\end{tabular}

Lr Leaf blast; $\mathrm{Nr}$ Ear blast and neck blast; Varieties, Representative donor variety containing the allele

${ }^{a}$ When Resistance ratio was greater than $85 \%$ and Resistance level was less than 2, NILs of allele materials were done

None, no functional Pi9 allele. Pi9-Type5 has three different type Pi9-Type5-Pi2, Pi9-Type5-Piz-t and Pi9-Type5. Donors of Pi9-Type5-Pi2, Pi9-Type5-Piz-t and Pi9-

Type5 carried Pi2, Piz-t and no genes, respectively. Donors of Pig-Type4 carried Pigm gene. Donors of Pig-Type8 carried Piz- $t$ gene

identified 13 novel alleles. The tandem-repeat region of the Pi2/Pi9 locus contains at least four cloned R genes (Pi2, Pi9, Piz-t, and Pigm) (Dai et al. 2010; Zhou et al., 2006) and is divided into the Pi2 locus and Pi9 locus. The Pi2 locus includes Pi2, Pigm, and Piz-t, while the Pi9 locus includes Pi9 (Xiao et al., 2017). We reasoned that these two loci may be functional sites for blastresistance. We identified no novel alleles at the Pi2 locus, which contained only the previously cloned genes
Pi2, Pigm, and Piz-t. Therefore, we focused on mining the Pi9 alleles, as this locus is a functional site that might represent the characteristics of these tandemrepeat regions. $P i 9$, a broad-spectrum rice blastresistance gene cloned by $\mathrm{Qu}$ in 2006 (Qu et al., 2006), has been used in China for many years and confers robust broad-spectrum resistance. Here, we sequenced the $M$. oryzae isolates collected from all over China and observed that almost all of the $M$. oryzae isolates contained 
the AvrPi9 gene, which was why donors of Pi9 showed broad-spectrum resistance. Therefore, isolating Pi9 alleles was of great significance for mining broadspectrum rice blast-resistance genes. Pi9 protein, like many disease resistance proteins, has a typical CC-NBSLRR domain. Since this is also true of most other cloned rice blast-resistance proteins, we predict that that only $P i 9$ alleles with complete CC-NBS-LRR domains are likely to confer resistance to rice blast.

The genomic sequences vary among the different $P i 9$ alleles, especially in the first intron, and there are many SNPs and large insertions or deletions in these alleles compared to the original $\mathrm{Pi} 9$ gene. However, in the first intron, due to the complex sequence results, it was difficult to amplify a single band with a sequence of about $840 \mathrm{bp}$. Considering that this region is located in the intron, it likely does not affect the translation of the protein, and since we already had about $9 \mathrm{~kb}$ of the sequence of the Pi9 allele, which could be used to distinguish the Pi9 allele, we gave up further attempting to sequence the $840 \mathrm{bp}$ fragments. The protein sequences of the Pi9 allele types are conserved, especially in the CC-NBS-LRR domain. None of the 13 Pi9 allele proteins have amino acid insertions/deletions in the CC or NBS domain, and we identified only one amino acid insertion in the LRR domains. In the CC domain, only Pi9-Type9 differs from Pi9, by four amino acids. Pi9-Type10/12/13 and Pi9 proteins have identical NBS domains, and Pi9Type9 has the most amino acid differences in this domain. The LRR region has more amino acid differences among the different allele types, with Pi9-Type5/8 having the most $(\sim 27)$ amino acid differences. Pi9-Type12 had the fewest amino acid differences (only 2).

The CC domain is particularly notable. Among the 13 newly identified Pi9 allele proteins, we detected only 4 amino acid differences between the Pi9-Type9 and Pi9 proteins and no differences in remaining $\mathrm{Pi} 9$ allele proteins, suggesting that the $\mathrm{CC}$ domain must be highly conserved. However, this region of the Pi9 gene contains the first intron, which has the greatest number of base mutations among the Pi9 alleles and a large number of insertions/deletions. It is interesting that this region has so much nucleotide sequence variation in the intron but is highly conserved in terms of amino acid sequence. By comparison, there are more amino acid differences in the LRR domain. The observation that the $\mathrm{CC}$ region is the most strictly conserved region of the CC-NBS-LRR domain suggests that it might be the most important region for disease resistance. When an amino acid in this region is changed, it could lead to the loss of disease resistance. The LRR domain might be less important; disease resistance might be maintained as long as a complete LRR domain is present, even if there are some amino acid changes. Because all of the Pi9 allele proteins contain a complete CC-NBS-LRR domain, we predict that they have the potential to confer broad-spectrum resistance to rice blast. Exploring such genotypes will help enrich our gene library for resistance to rice blast. After subsequent functional verification, we hope to use the alleles to improve resistance to rice blast.

\section{Allelic Variants of the R Gene Associated with Rice-Blast- Resistance}

We used rice blast resistant varieties of local cultivated rice, wild rice, and core germplasm resources for resistance gene mining Transferring resistance genes from resistant varieties to cultivated varieties can improve rice-blastresistance. Transferring individual genes or pyramiding multiple $\mathrm{R}$ genes can confer race-specific or broad spectrum resistances (Vasudevan et al., 2015). For example, the Pi54 allele from Oryza sativa cv Tetep conferred broadspectrum resistance against several rice-blast isolates compared to Pi54 orthologs from Oryza sativa cv Co39 (Thakur et al., 2015), suggesting allelic variants of Pi54 have functionally distinct capacities. Many studies have focused on mining single-copy rice blast-resistance genes, such as Pi54. However, due to the complex structure of the tandem-repeat region, few efforts at mining genes in this region have been successful.

In the current study, we attempted to mine homologous alleles of $\mathrm{Pi} 9$ in the tandem-repeat region from different variants based on the notion that this locus could represent the characteristics of these tandem-repeat regions. Thirteen novel alleles of $P i 9$ was identified (including three types of Pi9-Type5), significantly extending the known Pi9 allelic series. We used controlled infections to assess the resistance of rice varieties carrying the novel alleles. The varieties identified as being resistant in the nursery trials showed varied disease responses when infected with the single rice-blast isolate, suggesting that the novel $P i 9$ alleles vary in their blast-resistance spectra. Some of the novel alleles have unique SNPs, insertions, or deletions in addition to polymorphic residues that are shared between the different alleles. These variations are important for the durability of $P i 9$ against $M$. oryzae. The varied patterns among the rice varieties containing the novel $P i 9$ alleles to different rice-blast strains reveal their altered resistance spectra. However, this notion requires functional validation, such as transgenic verification, RNA expression analysis, or the construction of NILs.

Due to the distinct genomic structures (such as inversions and deletions) within the tandem-repeat regions of different rice varieties, it was difficult to clone these new alleles in the tandem repeat region. Furthermore, many R-genes with highly similar structures are tandemly duplicated with pseudogenes, which makes it challenging to distinguish candidate alleles from pseudogenes through a transcriptional assay like qRT-PCR. To clearly 
elucidate the function of these novel Pi9-like alleles and to circumvent the interference of other $\mathrm{R}$ genes, we constructed NILs to verify the resistance conferred by novel Pi9-like alleles at this locus. Through molecular-marker assisted backcrossing (MAB), we successfully pyramided seven Pi9 allele resistance genes, Pi9-Type3/4/5/6/9/10/ 11 , into the susceptible variant J23B to develop BC3F2 lines. These BC3F2 lines exhibited enhanced resistance to rice blast compared to the controls, suggesting that the broad-spectrum blast-resistance conferred was by these novel alleles was not attributable to other $\mathrm{R}$ genes.

\section{Current Status of Molecular Breeding for Rice-Blast- Resistance}

Rice blast, caused by the fungus $M$. oryzae, is one of the most important rice diseases worldwide (Ashkani et al., 2015; Shen et al., 2004). Rice blast has been reported in almost all rice-producing areas of the world (Miah et al., 2013; Zhu et al., 2000). Because the physiological races of rice-blast pathogen are highly variable and change rapidly, any gene conferring resistance to a single race is easily overcome (Wu et al., 2016; Xu et al., 2014). The breakdown of resistance can be avoided by developing rice varieties with a large number of broad-spectrum $R$ genes associated with strong resistance. This is of great importance for breeding disease-resistant rice varieties and preventing rice blast.

Rice blast-resistance genes generally encode proteins containing the CC-NBS-LRR domain, and we established that genes located in tandem-repeat regions of the genome often confer broad-spectrum resistance. Monoclonal rice blast-resistance genes such as Pi36 and Pi37 (Liu et al., 2007; Lin et al., 2007) usually do not offer lasting resistance. When these genes were transformed into susceptible receptor material using transgenic or traditional hybrid technology, the resistance of these plants was rapidly overcome by pathogenic microorganisms, resulting in loss of resistance (Zhu et al., 2000). The rice blast-resistance genes located in tandem repeat regions often have relatively robust broad-spectrum characteristics and can confer rice-blast-resistance in many regions for a long period of time (Mi et al., 2018; Zhou et al., 2018).

The arrangement of $\mathrm{R}$ genes in tandem-repeat regions, which often encode proteins with multiple CC-NBS-LRR domains with similar structures and functions (Dai et al. 2010), may help alleviate the loss of disease resistance caused by mutations of pathogenic microorganisms. However, this genetic structure makes it challenging to clone individual $\mathrm{R}$ genes. The Pi9 locus contains a dozen or so genes with similar structures that are connected in series to form a region of several hundred kilobases. These tandemly repeated genes can have as much as 99\% identity with each other (Dai et al. 2010), making it challenging to amplify and sequence a specific gene. Furthermore, the position of the Pi9 locus often differs significantly from its position in known reference genomes (9311, Nipponbare, MH63, ZS97, and other varieties) (Zhang et al., 2016), adding to the complexity of cloning these genes. After many attempts, our research group has now developed a method to stably amplify $P i 9$ allele genes from the tandem-repeat regions.

Using these techniques in this work, we screened 107 rice blast-resistant varieties from 1883 rice varieties and identified 13 novel Pi9 alleles (including three types of Pi9-Type5 alleles). Theoretically, different alleles of $P i 9$ will correspond to different tandem-repeat regions in the Pi9 locus. Since Pigm, Pi2, and Piz-t have been cloned, they are also located in the tandem repeats of this locus. To test the possibility that Pi9 alleles correspond to different tandem-repeat regions in the Pi2/Pi9 locus, we sequenced the Pigm, Pi2, and Piz-t genes from the donor materials of the 13 newly identified $P i 9$ alleles. Pi9-Type4 contained Pigm in the tandem repeat region, and Pi9-Type 8 contained Piz- $t$ in the tandem repeat region. Interestingly, Pi9-Type5 was located in three different tandem-repeat regions, including one containing Pi2, one containing Piz- $t$ and the other not containing any cloned gene. These results demonstrate that the structure of the Pi2/Pi9 locus is particularly complex, but homologue of the Pi9 allele are conservative and exist in many tandem repeat regions.

Our research group is currently developing chips that could be used to screen rice varieties for differences in the tandem repeat sequence flanking the Pi9 locus. This can further distinguish different tandem repeats in this region. It is challenging to clone a specific broad-spectrum rice blast-resistance gene in a tandem repeat. However, we used tandem-repeat sequencing results to develop a chip and combine the sequencing information from a relatively conserved genotype of the tandem-repeat region to distinguish among different tandem-repeat regions. Subsequently, the disease resistance of different tandem-repeat regions will be verified, and molecular-marker selection technology will be used to transform the tandem-repeat region with broad spectrum resistance into the susceptible receptor varieties. We therefore aim to confer broad-spectrum resistance to susceptible rice varieties using this technique.

\section{Conclusions}

Thirteen novel Pi9 alleles were identified from 107 blast resistance varieties through sequence-base allele mining. The developed NILs containing 5 novel Pi9 alleles fragments (Pi9-Type3, 4, 5, 6, 9, and 10) showed broadspectrum rice blast resistance in the field indicating its potentiality in rice blast resistance genetic improvement. Further studies are required to clone and characterize the functional alleles for the blast resistance. 


\section{Supplementary Information}

The online version contains supplementary material available at https://doi. org/10.1186/s12284-020-00442-z.

Additional file 1: Supplementary Table 1. Primers for sequence analysis of Pi9, Pi2, Pigm and Pizt allele genes in rice.Among them, the alleles of Pi2, Pigm and Piz- $t$ share a set of primers for amplification and sequencing; the alleles of Pi9 use a unique set of primers for amplification and sequencing. The primers used for PCR amplification and sequencing were clearly labelled and listed in the table

Additional file 2: Supplementary Table 2. The SSR primers used in molecular-marker assisted backcrossing (MAB). FAM and HEX are different fluorescent label.

Additional file 3: Supplementary Table 3. List of 107 rice varieties used for allele mining. Approximately 1883 varieties were grown at trial nurseries of Enshi and Yichang, Hubei Province. We identified 361 varieties from nurseries at Enshi or Yichang that displayed $H R$ or $R$ resistance phenotypes. A PCR-based screen for the presence of Pi2, Pi9, Pigm, or Piz-t identified 107 varieties as candidates for allele mining. The sequencing results of all 107 materials are shown in this table

Additional file 4: Supplementary Table 4. Sequence of Pi9 allele genes. The gap region in intron 1 replaced with the corresponding sequence of reference Pi9 sequence was shown in gray.

Additional file 5: Supplementary Table 5. Sequence of Pi9 allele proteins

Additional file 6: Supplementary Table 6. Primers for sequence analysis of AvrPi9 and AvrPiz-t genes in M. oryzae.The AvrPi9 and AvrPiz-t genes each use a unique set of primers for amplification and sequencing. The primers used for PCR amplification and sequencing were labelled and listed in the table.

Additional file 7: Supplementary Table 7. List the presence of AvrPi9 and AvrPiz-t genes in 34 M. oryzae.t, the gene is present in the M. oryzae; -, the gene does not exist in the $M$. oryzae.

\section{Abbreviations}

QTLs: Quantitative trait loci; NILs: Near-isogenic lines; R gene: Resistance gene; CC: Coiled-coil domain; NBS: Nucleotide-binding site; LRR: Leucine-rich repeats; HR: High resistance; R: Resistance; MR: Middle resistance; MS: Middle ensitivity; S: Sensitivity; HS: High sensitivity; BAC: Bacterial artificial chromosome; SNPs: Single nucleotide polymorphisms; InDels: Insertions and deletions; CDD: Conserved domains database; ORF: Open reading frame; qPCR: Quantitative polymerase chain reaction; MAB: Molecular-marker assisted backcrossing

\section{Acknowledgements}

We are very grateful to Professor Fasong Zhou from Greenfafa Company, Professor Sibin Yu and Professor Yongzhong Xing from Huazhong Agricultural University, and Professor Gonghao Jiang from Heilongjiang University for providing seeds for the donor parents of the blast-resistance cultivars.

\section{Authors' Contributions}

$Y Z$ and $W Y$ designed the experiments. $Y Z, F L, Q W$ and $W H$ performed the experiments. BY and $Y Z$ helped with field management. $Y Z$ and $F L$ analyzed the data. $Y Z$ and $W Y$ wrote the manuscript. All authors approved the manuscript.

\section{Funding}

This work was supported by grants from the Key Laboratory of Integrated Management of Crops of Central China and Hubei Key Laboratory of Crop Disease, Insect Pests and Weeds Control (Grant No. 2019ZTSJJ2) and the China Scholarship Council (CSC No. 201908420374).

\section{Availability of Data and Materials}

The data sets supporting the results of this article are included within the article and its supporting files.
Ethics Approval and Consent to Participate

Not applicable.

Consent for Publication

Not applicable.

\section{Competing Interests}

The authors declare that they have no competing interests

\section{Author details}

${ }^{1}$ College of Life Science and Health, Wuhan University of Science and Technology, Wuhan 430065, People's Republic of China. ${ }^{2}$ Institute of Model Animal of Wuhan University, Basic Medical School of Wuhan University, Wuhan 430071, People's Republic of China. ${ }^{3}$ Key Laboratory of Integrated Management of Crops of Central China, Ministry of Agriculture, Wuhan 430064, People's Republic of China. ${ }^{4}$ Hubei Key Laboratory of Crop Disease, Insect Pests and Weeds Control, Wuhan 430064, People's Republic of China. ${ }^{5}$ College of Life Sciences, Hubei University, Wuhan 430062, People's Republic of China.

Received: 30 April 2020 Accepted: 26 November 2020

Published online: 07 December 2020

\section{References}

Ashikawa I, Hayashi N, Yamane H, Kanamori H, Wu J, Matsumoto T, Ono K, Yano M (2008) Two adjacent nucleotide-binding site-leucine-rich repeat class genes are required to confer Pikm-specific rice blast-resistance. Genetics 180: 2267-2276

Ashkani S, Rafii M, Shabanimofrad M, Miah G, Sahebi M, Azizi P, Tanweer F, Akhtar M, Nasehi A (2015) Molecular breeding strategy and challenges towards improvement of blast disease resistance in rice crop. Front Plant Sci $6: 886$

Ballini E, More J, Droc G, Price A, Courtois B, Notteghem J, Tharreau D (2008) A genome-wide meta-analysis of rice blast-resistance genes and quantitative trait loci provides new insights into partial and complete resistance. MPMI 21(7):859-868

Bryan G, Wu K, Farrall L, Jia Y, Hershey H, McAdams S, Faulk K, Donaldson G, Tarchini R, Valent B (2000) A single amino acid difference distinguishes resistant and susceptible alleles of the rice blast-resistance gene Pi-ta. Plant Cell 12:2033-2045

Chen X, Jia Y, Jia M, Pinson S, Wang X, Wu B (2018a) Functional interactions between major rice blast-resistance genes, $P i$-ta and $P i-b$, and minor blastresistance quantitative trait loci. Phytopathology 108:1095-1103

Chen X, Shang J, Chen D, Lei C, Zou Y, Zhai W, Liu G, Xu J, Ling Z, Cao G, Ma B, Wang Y, Zhao X, Li S, Zhu L (2006) A ß-lectin receptor kinase gene conferring rice blast-resistance. Plant J 46:794-804

Chen Z, Zhao W, Zhu X, Zou C, Yin J, Chern M, Zhou X, Ying H, Jiang X, Li Y, Liao H, Cheng M, Li W, He M, Wang J, Wang J, Ma B, Wang J, Li S, Zhu L, Chen X (2018b) Identification and characterization of rice blast-resistance gene Pid4 by a combination of transcriptomic profiling and genome analysis. J Genet Genomics 45:663-672

Dai L, Wu J, Li X, Wang X, Liu X, Jantasuriyarat C, Kudrna D, Yu Y, Wing R, Han B, Zhou B, Wang G (2010) Genomic structure and evolution of the Pi2/9 locus in wild rice species. Theor Appl Genet 121:295-309

Deng Y, Zhai K, Xie Z, Yang D, Zhu X, Liu J, Wang X, Qin P, Yang Y, Zhang G, Li Q, Zhang J, Wu S, Milazzo J, Mao B, Wang E, Xie H, Tharreau D, He Z (2017) Epigenetic regulation of antagonistic receptors confers rice blast-resistance with yield balance. Science 355:962-965

Deng Y, Zhu X, Shen Y, He Z (2006) Genetic characterization and fine mapping of the blast-resistance locus Pigm(t) tightly linked to Pi2 and Pi9 in a broadspectrum resistant Chinese variety. Theor Appl Genet 113:705-713

Fukuoka S, Saka N, Koga H, Ono K, Shimizu T, Ebana K, Hayashi N, Takahashi A, Hirochika H, Okuno K, Yano M (2009) Loss of function of a proline-containing protein confers durable disease resistance in rice. Science 325:998-1001

Hayashi K, Yoshida H (2009) Refunctionalization of the ancient rice blast disease resistance gene Pit by the recruitment of a retrotransposon as a promoter. Plant J 57:413-425

Hayashi N, Inoue H, Kato T, Funao T, Shirota M, Shimizu T, Kanamori H, Yamane H, Hayano-Saito Y, Matsumoto T, Yano M, Takatsuji H (2010) Durable panicle blast-resistance gene Pb1 encodes an atypical CC-NBS-LRR protein and was 
generated by acquiring a promoter through local genome duplication. Plant J 64:498-510

Hittalmani S, Parco A, Mew T, Zeigler R, Huang N (2000) Fine mapping and DNA marker-assisted pyramiding of the three major genes for blast-resistance in rice. Theor Appl Genet 100:1121-1128

Hua L, Wu J, Chen C, Wu W, He X, Lin F, Wang L, Ashikawa I, Matsumoto T, Wang L, Pan Q (2012) The isolation of Pi1, an allele at the Pik locus which confers broad spectrum resistance to rice blast. Theor Appl Genet 125:1047-1055

Inoue H, Nakamura M, Mizubayashi T, Takahashi A, Sugano S, Fukuoka S, Hayashi N (2017) Panicle blast 1 (Pb1) resistance is dependent on at least four QTLS in the rice genome. Rice 10:36

IRRI (2002) Standard evaluation system for rice. IRRI, Manila

Ishihara T, Hayano-Saito Y, Oide S, Ebana K, La N, Hayashi K, Wang L, Ashikawa I, Matsumoto T, Wang L, Koizumi S (2014) Quantitative trait locus analysis of resistance to panicle blast in the rice cultivar Miyazakimochi. Rice 7:2

Jiang J, Mou T, Yu H, Zhou F (2015) Molecular breeding of thermo-sensitive genic male sterile (TGMS) lines of rice for blast-resistance using Pi2 gene. Rice 8:11

Jiang $N$, Li Z, Wu J, Wang Y, Wu L, Wang S, Wang D, Wen T, Liang Y, Sun P, Liu J, Dai L, Wang Z, Wang C, Luo M, Liu X, Wang G (2012) Molecular mapping of the Pi2/9 allelic gene Pi2-2 conferring broad-spectrum resistance to Magnaporthe oryzae in the rice cultivar Jefferson. Rice 5:29

Lee S, Song M, Seo Y, Kim H, Ko S, Cao P, Suh J, Yi G, Roh J, Lee S, An G, Hahn T, Wang G, Ronald P, Jeon J (2009) Rice Pi5-mediated resistance to Magnaporthe oryzae requires the presence of two coiled-coil-nucleotidebinding-Leucine-rich repeat genes. Genetics 181:1627-1638

Li W, Zhu Z, Chern M, Yin J, Yang C, Ran L, Cheng M, He M, Wang K, Wang J, Zhou X, Zhu X, Chen Z, Wang J, Zhao W, Ma B, Qin P, Chen W, Wang Y, Liu J, Wang W, Wu X, Li P, Wang J, Zhu L, Li S, Chen X (2017) A natural allele of a transcription factor in rice confers broad-spectrum blast-resistance. Cell 170: $114-126$

Librado P, Rozas J (2009) DnaSP: v5 a software for comprehensive analysis of DNA polymorphism data. Bioinformatics 25:1451-1452

Lin F, Chen S, Que Z, Wang L, Liu X, Pan Q (2007) The blast-resistance gene Pi37 encodes a nucleotide binding site-leucine-rich repeat protein and is a member of a resistance gene cluster on rice chromosome 1. Genetics 177: 1871-1880

Liu G, Lu G, Zeng L, Wang G (2002) Two broad-spectrum blast-resistance genes, Pig(t) and Pi2(t), are physically linked on rice chromosome 6. Mol Gen Genomics 267:472-480

Liu X, Lin F, Wang L, Pan Q (2007) The in Silico map-based cloning of Pi36, a rice coiled-coil-nucleotide-binding site-leucine-rich repeat gene that confers racespecific resistance to the blast fungus. Genetics 176:2541-2549

Mi J, Yang D, Chen Y, Jiang J, Mou H, Huang J, Ouyang Y, Mou T (2018) Accelerated molecular breeding of a novel P/TGMS line with broad-spectrum resistance to rice blast and bacterial blight in two-line hybrid rice. Rice 11:11

Miah G, Rafii M, Ismail M, Puteh A, Rahim H, Asfaliza R, Latif M (2013) Blastresistance in rice: a review of conventional breeding to molecular approaches. Mol Biol Rep 40:2369-2388

Murray M, Thompson W (1980) Rapid isolation of high molecular weight plant DNA. Nucleic Acids Res 8:4321-4325

Qu S, Liu G, Zhou B, Bellizzi M, Zeng L, Dai L, Han B, Wang G (2006) The broadspectrum blast-resistance gene Pi9 encodes an NBS-LRR protein and is a member of a multigene family in rice. Genetics 172:1901-1914

Sasaki R (1922) Existence of strains in rice blast fungus. Int J Plant Prot (Tokyo) 9: 631-644

Sharma T, Madhav M, Singh B, Shanker P, Jana T, Dalal V, Pandit A, Singh A, GaikwadK UH, Singh N (2005) High-resolution mapping, cloning and molecular characterization of the Pi-kh gene of rice, which confers resistance to Magnaporthe grisea. Mol Gen Genomics 274:569-578

Shen M, Lin J (2004) The economic impact of rice blast disease in China. In: Zeigler R, Leong S, Teng P (eds) Rice Blast Disease. CAB international/IRRI, Wallingford, U.K, pp 321-331

Thakur S, Singh P, Das A, Variar M, Prashanthi S, Singh A, Singh U, Chand D, Singh N, Sharma T (2015) Extensive sequence variation in rice blast-resistance gene Pi54 makes it broad spectrum in nature. Front Plant Sci 6:345

Tian D, Chen Z, Chen Z, Zhou Y, Wang Z, Wang F, Chen S (2016) Allelespecific marker-based assessment revealed that the rice blast-resistance genes Pi2 and Pig have not been widely deployed in Chinese indica rice cultivars. Rice 9:19
Vasudevan K, Gruissem W, Bhullar NK (2015) Identification of novel alleles of the rice blast-resistance gene Pi54. Sci Rep 5:15678

Wang G, Valent B (2017) Durable resistance to rice blast. Science 355:906-907

Wang Z, Yano M, Yamanouchi U, Iwamoto M, Monna L, Hayasaka H, Katayose Y, Sasaki T (1999) The Pib gene for rice blast-resistance belongs to the nucleotide binding and leucine-rich repeat class of plant disease resistance genes. The Plant J 19:55-64

Wu K, Xu T, Guo C, Zhang X, Yang S (2012) Heterogeneous evolutionary rates of Pi2/9 homologs in rice. BMC Genet 13:73

Wu Y, Yu L, Pan C, Dai Z, Li Y, Xiao N, Zhang X, Ji H, Huang N, Zhao B, Zhou C, Liu G, Liu X, Pan X, Liang C, Li A (2016) Development of near-isogenic lines with different alleles of Piz locus and analysis of their breeding effect under Yangdao 6 background. Mol Breed 36(2):12

Xiao N, Wu YY, Pan CH, Yu L, Chen Y, Liu GQ, Li YH, Zhang XX, Wang ZP, Dai ZY, Liang CZ, Li AH (2017) Improving of rice blast-resistances in japonica by pyramiding major R genes. Front Plant Sci 7:1918

Xu X, Lv Q, Shang J, Pang Z, Zhou Z, Wang J, Jiang G, Tao Y, Xu Q, Li X, Zhao Z, Li S, Xu J, Zhu L (2014) Excavation of Pid3 Orthologs with differential resistance spectra to Magnaporthe oryzae in rice resource. Plos One 9(3): e93275

Yamasaki Y, Kiyosawa S (1966) Studies on inheritance of resistance of rice varieties to blast I. inheritance of resistance of Japanese varieties to several strains of the fungus (in Jappanese). Bull Natl Inst Agric Sci D 14:39-69

Yu H, Xie W, Li J, Zhou F, Zhang Q (2014) A whole-genome SNP Array (RICE6K) for genomic breeding in RICE. Plant Biotechnol J 12:28-37

Zhang J, Chen L, Xing F, Kudrna D, Yao W, Copetti D, Mu T, Li W, Song J, Xie W, Lee S, Talag J, Shao L, An Y, Zhang C, Ouyang Y, Sun S, Jiao W, Lv F, Du B, Luo M, Maldonado C, Goicoechea J, Xiong L, Wu C, Xing Y, Zhou D, Yu S, Zhao Y, Wang G, Yu Y, Luo Y, Zhou Z, Hurtado B, Danowitz A, Wing R, Zhang $Q$ (2016) Extensive sequence divergence between the reference genomes of two elite indica rice varieties Zhenshan 97 and Minghui 63. Proc Natl Acad Sci U S A 113:5163-5171

Zhao H, Wang X, Jia Y, Minkenberg B, Wheatley M, Fan J, Jia M, Famoso A, Edwards J, Yeshi W, Valent B, Wang G, Yang Y (2018) The rice blast-resistance gene Ptr encodes an atypical protein required for broad-spectrum disease resistance. Nat Commun 9:2039

Zhao H, Yao W, Ouyang Y, Yang W, Wang G, Lian X, Xing Y, Chen L, Xie W (2015) RiceVarMap: a comprehensive database of rice genomic variations. Nucleic Acids Res 43:1018-1022

Zhou B, Qu S, Liu G, Dolan M, Sakai H, Lu G, Bellizzi M, Wang G (2006) The eight amino-acid differences within three leucine-rich repeats between Pi2 and Piz$t$ resistance proteins determine the resistance specificity to Magnaporthe grisea. Mol Plant MicrobeE In 19:1216-1228

Zhou X, Jiang G, Yang L, Qiu L, He P, Nong C, Wang Y, He Y, Xing Y (2018) Gene diagnosis and targeted breeding for blast-resistant Kongyu 131 without changing regional adaptability. J Genet Genomics 45:539-547

Zhu Y, Chen H, Fan J, Wang Y, Li Y, Chen J, Fan J, Yang S, Hu L, Leung H, Mew T, Teng P, Wang Z, Mundt C (2000) Genetic diversity and disease control in rice. Nature 406(6797):718-722

\section{Publisher's Note}

Springer Nature remains neutral with regard to jurisdictional claims in published maps and institutional affiliations.

\section{Submit your manuscript to a SpringerOpen ${ }^{\circ}$ journal and benefit from:}

- Convenient online submission

- Rigorous peer review

- Open access: articles freely available online

- High visibility within the field

- Retaining the copyright to your article

Submit your next manuscript at $\boldsymbol{\nabla}$ springeropen.com 